\title{
Study on Application of Flexibility Theory in Business English Translation Education Field
}

\author{
Hong Liu \\ College of Foreign Languages and Literature, Wuhan Donghu University, Wuhan Hubei, 430212, \\ China
}

Keywords: Flexibility theory, Business English, Translation education, Research.

\begin{abstract}
As the rate of economic development speeds up continuously, the activities of economy and trade also become more and more frequent. English quality and ability training for talents also enhance. Thus, business English receives more and more attention in current education field. However, with social progress, English translators of complete translation cannot meet relevant social demands. Thus, translation education workers need to improve guidance of flexibility theory for students. This paper simply analyzes connotation and translation principles of business English and flexibility theory, and intensively states the application strategy of flexibility theory in business English so as to assist education workers to improve awareness and cognition and optimize actual function of business English.
\end{abstract}

\section{Introduction}

Economic globalization fundamentally drives positive growth of China's economy and also brings trade contacts. Relevant enterprises should improve trading ability. Meanwhile, relevant English translation talents should optimize their translation level. Obsolete translation mode cannot adapt current translation requirement. The society formulates more detailed standards for the ability of translation talents. Based on corresponding social background, it is required to make sure flexibility theory and business English translation form benignant discipline integration and establish more systematic and superior translation teaching.

\section{Era significance and basic procedure of flexibility theory}

Era significance of flexibility theory.

The connotation of flexibility theory is to effectively describe the meaning of original text on the basis of understanding the implication of original text, and process the emotion and thought of original text, instead of resting on simple language structure. Thus, relevant translation personnel need to effectively cognize and deconstruct basic content. Flexibility theory overturns traditional translation mode and abandons original straightforward translation. Only when both-way optimization of flexible translation theory and practice is achieved can the promotion of flexibility theory for translation education can be further optimized ${ }^{[1]}$. Compared with traditional translation mode, flexibility theory is a simplified translation mode. Different from original free translation and literal translation, flexibility theory has diversified translation skills, and can achieve more flexible and diversified translation patterns and make sure basic articles get better structure. Artistic conception and lasting appeal of original text are kept, and basic purpose of translation is achieved. Relevant translation personnel should rationally integrate translation contents and output relevant contents more freely.

Flexible translation includes flexibility and translation. Relevant translators need to achieve improvement of language flexibility according to special language environment and requirements. On the one hand, translators should flexibly cope with corresponding problems in the complete translation process and tendentiously deepen cognition of basic materials. On the other hand, translators should fully know readers' basic needs, form microcosmic translation output, make sure entire means and information intensity can adapt corresponding translation requirements and really realize optimal deconstruction of basic content. 


\section{Basic procedure of flexibility theory.}

Flexibility theory is actually a translation process. Further translation and planning are conducted through basic original materials. The original title can be properly reserved. As well, proper adjustment of main idea after translation can be carried out. Corresponding translators should conduct proper structure innovation and content enriching on the basis of cognizing basic concepts. Procedure control lies in professional quality of translators. Translators should not just analyze and deconstruct basic content in a detailed way, but also should adapt the development requirements of whole market. Readers' favor can be gained only through improving complete translation content ${ }^{[2]}$.

\section{Era significance and basic content of business English}

\section{Era significance of business English.}

For business English, basic training direction is English. But in actual teaching process, many business elements and business knowledge will be integrated, and a large number of business grammar points will be generated. Translators should not only master over all English translation skills, but also well absorb and organize basic business knowledge in order to achieve smooth translation procedure ${ }^{[3]}$. Economic development brings lots of business communications. In the communication, basic work of translation is to intensively translate and repeat the content of business negotiations. Translation deviation will influence the trend of overall business negotiations and even result in immeasurable economic losses. Thus, business English is an important language tool in business activity and also an important constituent part of prompting the business activity.

During using business English, firstly, it is required to ensure completeness and richness of basic meaning, achieve full translation of main idea, master the center of the article, carry out refined processing and optimally present potential culture of the article. Secondly, professional skills should be applied to control use of basic terms, guarantee correct translation of economic, legal and trading items and form equal term output. Translators should not just comprehensively master the entire content and intensively cognize the details. Finally, translators should concisely express basic statements, grasp basic communication time, establish the most efficient output structure and achieve popular expression. Too long theory and excessively gorgeous modifier cannot be used. Translation should be concise and comprehensive.

\section{Basic content of business English.}

In English translation process, basic translation principles should be guaranteed, and intensive output of corresponding content should be conducted according to basic norms. Firstly, essential accuracy principle should be guaranteed. Relevant translators should read the article entirely, strive to stand in the same information expression structure system with the author and apply professional grammar to embellish the entire content. In the translation process, translators should intensively master relevant knowledge connotation and ensure translation effect on the basis of accurate translation $^{[4]}$. Secondly, basic specialty principle should be guaranteed. For the application of business English, translation process involves a wide scope of knowledge, including economics, philosophy, accounting and management. Thus, relevant translators should optimize professional knowledge theory and comprehensively improve practical translation level in the translation process. Besides, translators should display corresponding professional quality and really achieve their important status in trading communication. Thirdly, basic proforma principle should be ensured. For business English, basic proforma principle is very important. In practical translation process, translators cannot innovate blindly for the purpose of innovation, but should carry out rational skill upgrade on the basis of basic translation principles. If translators encounter problems in the translation process, they should loop up corresponding materials to ensure real and effective translation content. 


\section{Application strategy of flexibility theory in business English translation teaching}

\section{Translation mode - extractive translation.}

For translation, to ensure structure completeness of translation content, translators should intensively read basic translation text and then extract the essence. Through intensive translation of important units and items, translators can ensure connotation and depth of translation content. In statement translation process, basic phrases and sentences should be optimally screened. Based on guaranteeing complete paragraph, language should be simplified. Relevant translators should globally grasp the article and effectively delete contents according to basic market conditions and environment. Relevant translators should utilize optimized translation mode and structure to promote explicit article content, save translation time and improve work efficiency ${ }^{[5]}$.

\section{Translation mode - descriptive translation.}

Under the support of flexibility theory, descriptive translation plays a critical role. Due to cultural and regional difference, translators should apply entire connotation in a compressed way and delete some contents. Relevant translators should intensively integrate many tacit contents and optimally polish basic language. Translators should grasp basic translation thought and recombine basic materials, flexibly apply characters through free recombination and properly modify the article on the basis of respective original text.

\section{Translation mode - rewriting-type translation.}

Translators should carefully analyze the works translated and pay attention to basic annotation and statement. Rewriting-type translation is not simple creation, but expansive description of basic content so as to influence presentation of connotation of translations works. Basic rewriting-type translation can effectively expand essential spirit of works, offer more far-reaching value structure for basic translation work and achieve completeness of translation works based on making sure the translation works comply with translation effect.

Translation mode - reference-type translation.

In the translation process, translators cannot blindly carry out literal translation, but should conduct optimal resource allocation for basic data. In the face of mixed reference data, it is required to mark the important clues. Translators should not just analyze and summarize the background of reference data, but also fully deconstruct the essential content of theme content. In addition, during referring to references, translators should explain the quotation in detail and fundamentally guarantee integrity of translated text.

\section{Translation mode - comment-type translation.}

Translation work is not accomplished in an action. Relevant translators should further polish transition works and effectively correct basic grammar and expression. During re-reading translation works, translators should fully understand the connotation of the entire works and then intensively modify the works according to the background, creation environment and basic reader group. In the operation process of comment-type translation, social sciences and literature field should be studied in a detailed way and the entire works is modified in accordance with the mode of translation, opinion, translation comment and self-comment.

\section{Translation mode - statement-type translation.}

In the translation process, basic statement-type translation aims to make readers better seek corresponding view and word explanations in the article and promote them to better know the connotation of the article. Some implicit expressions should be obviously changed so that readers can further know and cognize the entire content of the article. In statement-type translation process, the statement of words and paragraphs is to intensively express basic background gap and literature quotation. Most statement-type translations will appear in the ending of translated article. In this way, readers can make the best of statement-type translation to seek the content in the reading process and well grasp the whole article. Translators' translation means can effectively promote readers to cognize basic text content and more profoundly know it.

\section{Translation mode - compression-type translation.}

In the translation modes, compression-type translation is very common. As the whole pace of society speeds up, people' s requirement for reading time becomes increasingly high. Thus, relevant 
translators should adopt corresponding compression-type translation and achieve the latest time consumption under the condition of making sure people fully know basic translation content. For compression-type translation mode, relevant translators need to improve their translation ability and achieve effective output of core information on the basis of guaranteeing complete basic data. Relevant translators should optimize basic translation situation and apply compression-type summarization and flexible method to carry out optimal translation of business English content.

\section{Translation mode - conversion-type translation.}

In the process of translating basic works, the key is to know the entire article, achieve real and effective translation and reach the basic requirements so as to further promote smooth and complete translation. During choosing sentence structure and grammar, information effectiveness shook be focused on, and basic equivalent information is improved in actual business activities. Besides, in the translation process, translators need to apply conversion-type translation, achieve data completeness and optimization under the precondition of equivalent output, truly restore accurate information of whole data and establish sound translation structure.

\section{Translation mode - editing-type translation.}

In the translation process, editing-type translation process not just translates and repeats basic works. Relevant translators are required to overall translate the article. The corresponding author is hoped to apply further data to apply corresponding content. Thus, relevant translators should extract corresponding content and key points in the miscellaneous knowledge library, carry out editing-type translation and make sure the main idea remains unchanged for the convenience of understanding the article. In the basic translation process, marks should be made according to the main idea of the article. Meanwhile, it is required to intensively convert the content consulted and form the time-consuming, convenient and fast translation process, which is further beneficial to optimizing reading and understanding of articles.

\section{Conclusion}

In one word, the application of flexibility principle in business English adapts era development. Not just can reading mode be optimized, but also the whole reading efficiency can improve. Moreover, it is more beneficial to development of business translation career. The whole translation process is simplified fundamentally. Thus, in business translation process, full application flexibility principle can rally achieve functional optimization of translation.

\section{References}

[1] Zhang Kun, Applications of flexibility theory in business English translation, E-journal of New Education Era (teacher edition), 2014,14(08):287-288.

[2] Liu Yanyan, On application of flexibility theory in business English translation, Journal of JiLin Radion and TV University, 2016,23(01):93-94.

[3] Wang Yan, Study on business English translation based on flexibility theory, Course Education Research, 2015,18(31):101-102.

[4] Hao Junwen, On language flexibility in English-Chinese translation - case study of Shanxi folk literature in List of Intangible Cultural Heritage IN Shanxi Province, Shanxi University, 2013.

[5] Wang Yue, Analysis on flexible application of three-stage task-driven teaching method in middle school English teaching, Asia-Pacific Journal of Education, 2015,22(10):49-49. 